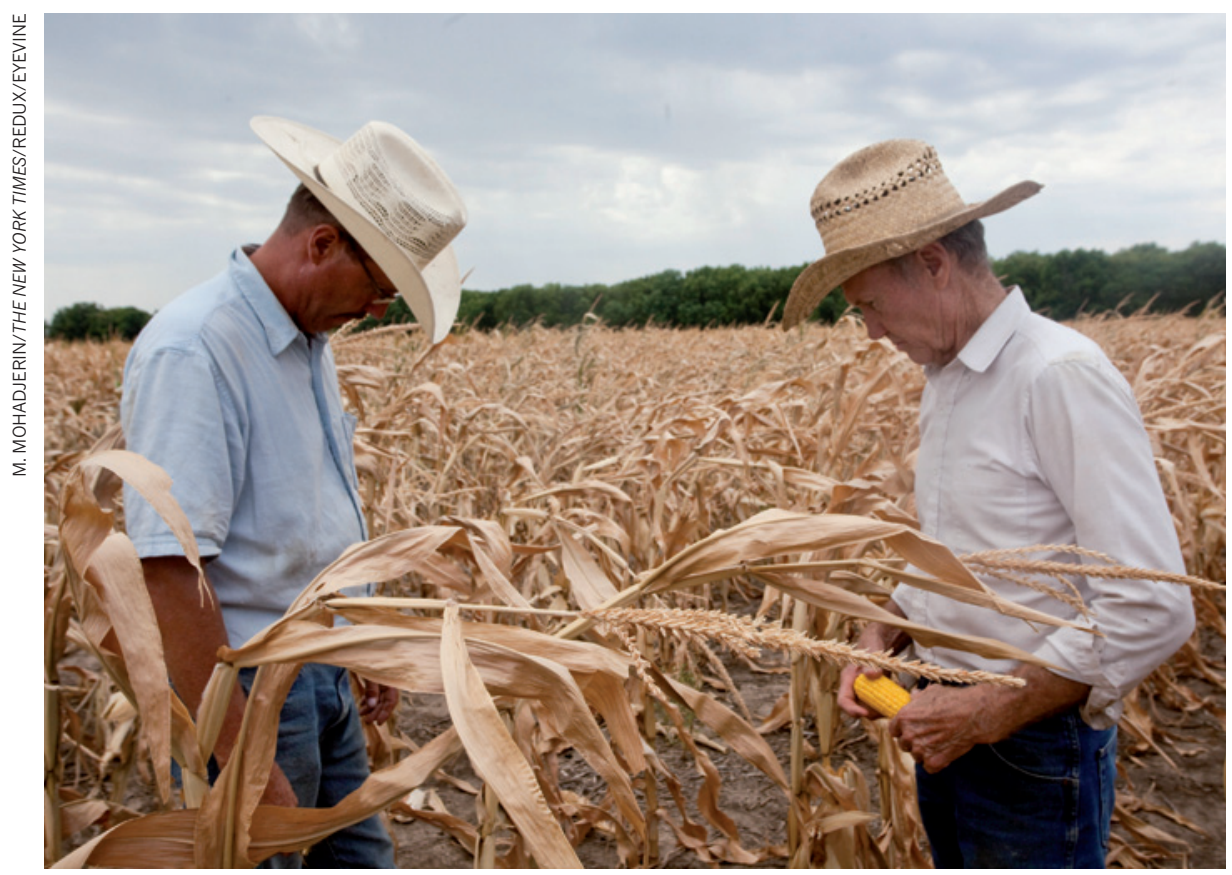

Droughts are becoming more frequent in parts of the United States.

CLIMATE CHANGE

\title{
Heatwaves blamed on global warming
}

\section{Unusually high frequency points to human influence.}

\section{BY JEFF TOLLEFSON}

$\mathrm{N}$ ASA climatologist James Hansen made headlines during the US heatwave of 1988, declaring in testimony to Congress and during interviews on primetime television that a build-up of greenhouse gases was increasing the probability of weather extremes. Now, as much of the United States sizzles through another torrid summer and the Midwest endures a historic drought, Hansen, director of NASA's Goddard Institute for Space Studies in New York, claims that the future he predicted has arrived.

"The climate dice are now loaded to a degree that a perceptive person old enough to remember the climate of 1951-1980 should recognize the existence of climate change, especially in summer," he and his colleagues write in a paper entitled 'Perceptions of Climate Change ${ }^{11}$ published on 6 August. Just days earlier, on 1 August, Republican senators had challenged mainstream climate scientists over the existence of anthropogenic global warming at a hearing in Washington DC, underscoring the stubborn political divide over climate policy. Just as he did 24 years ago, Hansen has plunged into the debate, pre-empting the publication of his study with an opinion article in The Washington Post'.

Hansen's team used seasonal temperature records for 1951-80, a period of relatively stable climate, as a baseline, then analysed the frequency and scale of subsequent temperature anomalies. On average, the team concludes, the globe has warmed by only about $0.5-0.6^{\circ} \mathrm{C}$ since that time, but the shift has had a significant impact on many parts of the world (see 'What a scorcher').

Extremely hot summers - classified as about $3.5^{\circ} \mathrm{C}$ warmer than average - have affected about $10 \%$ of the world's land since 2006, an order of magnitude higher than during the period from 1951 to 1980.

The study is not the first to show a link between global warming and extreme weather ${ }^{3}$, but it goes well beyond its predecessors, concluding that greenhouse gases alone are responsible for the hot summers and heatwaves. "The likelihood that these events would have occurred without global warming is minuscule," Hansen says.

A poll by researchers at Yale University in New Haven, Connecticut, and George Mason University in Fairfax, Virginia, suggests that most people in the United States accept the link between hot weather and global warming ${ }^{4}$. But Hansen's assertion is running into some heavy weather among scientists.

Martin Hoerling, a meteorologist at the National Oceanic and Atmospheric Administration in Boulder, Colorado, calls Hansen's paper an "extended Op-Ed piece", arguing that the broader climate record does not support the link to individual heatwaves. Last year, Hoerling co-authored a paper ${ }^{5}$ suggesting that the 2010 drought in Russia was so far outside the realm of normal weather that the small rise in global temperatures could not account for it. He says that natural variability can explain most extremes, and that global warming merely enhances them.

Hansen notes that his study is purely statistical and does not try to explain how climate change could cause extremely hot summers. Kevin Trenberth, a climatologist at the US National Center for Atmospheric Research (NCAR) in Boulder, says that Hansen's statistics are illustrative of a trend that should help people to understand global warming and the profound effect humans have had on the climate system. "It is never due to humans alone, nor is it ever, these days, just natural variability."

In a paper to be published in the Journal of Geophysical Research ${ }^{6}$, Trenberth and a

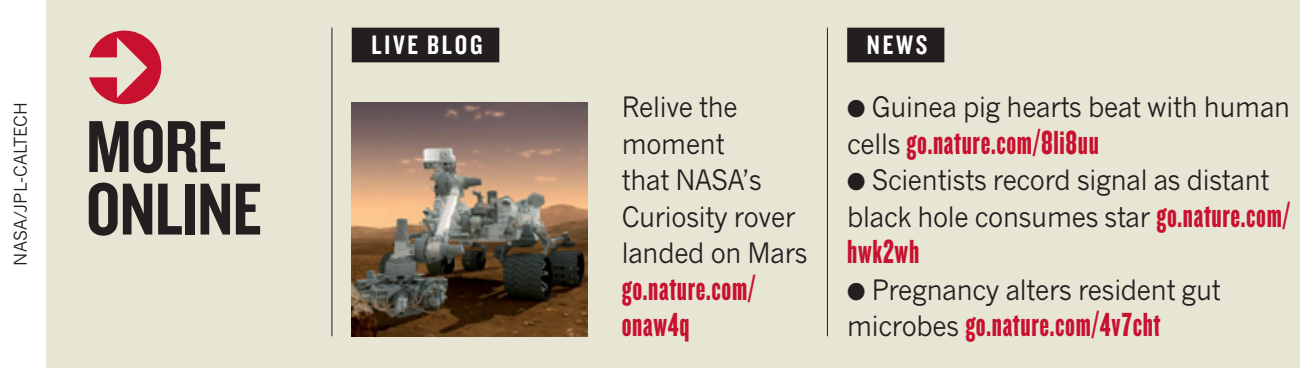

\section{OLYMPICS}

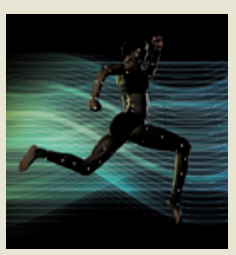

Nature takes a look at how research has shaped the events at London 2012 go.nature.com/1hgovl 


\section{WHAT A SCORCHER}

Between June and August 2010, extremely high temperatures (brown) hit about $13 \%$ of Earth's surface, an area roughly ten times greater than in 1951-80.

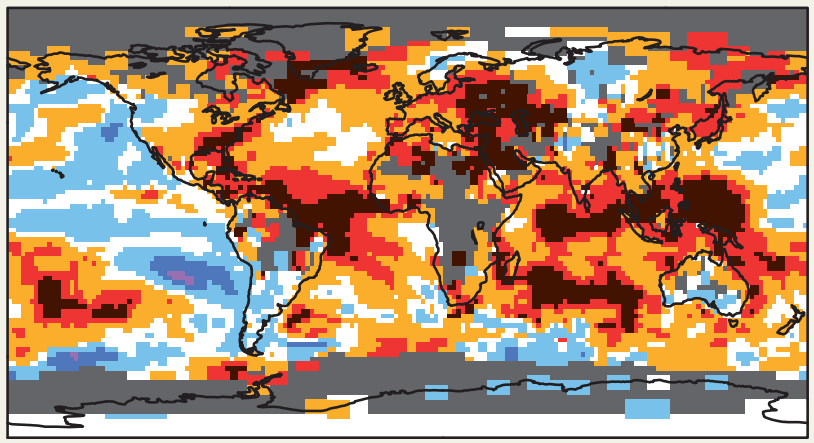

team of researchers investigate the physical mechanisms that drove some extreme weather events in 2010. Using a climate model developed at the NCAR, the team investigated links between a pair of El Niño and La Niña events (in which warm or cold surface waters, respectively, built up in the eastern Pacific Ocean) and weather events such as stronger monsoons in Asia and droughts in Russia and the Amazon. Although he thinks that global warming could have a role in such extreme events, Trenberth says that climate models have not yet been able to tease out the details.

"Models have a hard time doing extremes well," Trenberth says. But because of limited data sets for extreme weather and inadequate climate models, he worries that some people could draw the wrong conclusion: "that there is no human influence".

1. Hansen, J., Sato, M. \& Ruedy, R. Proc. Natl Acad. Sci. USA http://dx.doi.org/10.1073/pnas.1205276109 (2012).

2. Hansen, J. E. The Washington Post (5 August 2012).

3. Schiermeier, Q. Nature 477, 148-149 (2011).

4. Leiserowitz, A., Maibach, E., Roser-Renouf, C. \& Hmielowski, J. Global Warming's Six Americas, March 2012 \& Nov. 2011 (Yale Univ. \& George Mason Univ, 2012)

5. Dole, R. et al. Geophys. Res. Lett. 38, L06702 (2011)

6. Trenberth, K. E. \& Fasullo, J. J. Geophys. Res.

http://dx.doi.org/10.1029/2012JD018020 (in the press).

\section{AWARDS}

Physics prize
dwarfs all others

\section{Theorists left reeling after billionaire reveals massive prize.}

\section{BY GEOFF BRUMFIEL}

$\mathrm{W}$

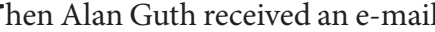
from a colleague asking if he could discuss a new annual prize in physics, he recalls, "I thought I was being asked to be on an organizing committee".

Instead, the other physicist, Nima ArkaniHamed at the Institute for Advanced Study in Princeton, New Jersey, told Guth that they were among the winners of a US\$3-million award. Guth, a theorist at the Massachusetts Institute of Technology in Cambridge who introduced the idea of cosmic 'inflation', assumed that the prize would be split. But Arkani-Hamed surprised him again: they had won $\$ 3$ million each. "Do you mean that I just won $\$ 3$ million and that you just won $\$ 3$ million?" Guth asked, incredulously. "He said 'yes"”

"At that point I just kind of fell off my seat," Guth says.

Last week's public announcement of the prize, which was awarded to nine physicists, was just as sudden (see go.nature.com/ mwaays). On 31 July, two weeks after Guth's unexpected conversation, stories appeared in The New York Times and The Guardian unveiling the \$27-million Fundamental Physics
Prize, which dwarfs all other prizes in science. Shortly afterwards, a bare-bones website appeared. Under the heading 'board', it listed just two people: Steven Weinberg, a Nobelprizewinning theorist at the University of Texas at Austin, and a man named Yuri Milner.

It was Milner, a 50-year-old Russian Internet entrepreneur, who founded the prize and chose the first winners (Weinberg was appointed to the board only after Guth and the others were notified). In his youth, Milner spent a decade studying theoretical physics in the Soviet Union before abandoning his $\mathrm{PhD}$ to move into the private sector. His early investments included a macaroni factory and a Russian e-mail portal, but Milner's fortune was sealed in 2009 when his firm bought a \$200-million stake in the social-media site Facebook. In May, Facebook began trading publicly, and Milner's company made an estimated $\$ 1.7$ billion. Today, his investment funds are valued at $\$ 12$ billion, and his personal wealth at around $\$ 1$ billion.

Milner never forgot his early years working on quantum chromodynamics, a theoretical framework that describes the interactions of quarks and gluons. For years he had toyed with the idea of creating a prize and, in recent months, he decided to act on it, choosing nine theorists who have never won Nobel prizes, but whose work he considers to be groundbreaking. "It was clear that he'd done a lot of homework," Arkani-Hamed says. "He knew an impressive amount about what was going on."

"The intention was to say that science is as important as shares trading on Wall Street," Milner told Nature. The prize money comes with no strings attached, although Milner hopes that the theorists will contribute to a new lecture series for the public. Milner also plans to create an annual \$100,000 New Horizons prize for young researchers and an ad hoc version of the Fundamental Physics Prize that can be won at any time "in exceptional cases", the website says. According to the rules of the prizes, anyone can be nominated, and future prizewinners will be selected by a committee of all previous ones.

"He's recognizing that there are some very smart people who have done some very clever things," says George Smoot, a physicist at the University of Paris Diderot who shared the 2006 Nobel Prize in Physics. But, he adds, giving such a large prize to top theorists, many of whom are late in their career, will not revolutionize theoretical physics. Smoot, who donated his portion of the Nobel prize to charity, says that he would have liked to have seen Milner put half of the \$27 million into fellowships for young researchers. Arkani-Hamed says that Milner is aware of the criticisms but felt that other philanthropists have created fellowships and institutes, and he wanted the new prize to stand apart.

For his part, Guth says that he hasn't yet decided what to do with the money, which was deposited directly into his bank account while he and his wife were away at a local Shakespeare festival. "We're still kind of in shock," he says. 